DOI 10.37882/2223-2982.2021.11-2.20

\title{
СПЕЦИФИКА СЛОВООБРАЗОВАТЕЛЬНЫХ ПРОЦЕССОВ В СОВРЕМЕННОМ АНГЛИЙСКОМ И НЕМЕЦКОМ ЯЗЫКАХ
}

\section{THE SPECIFICS OF WORD FORMATION IN MODERN ENGLISH AND GERMAN}

\section{O. Litvjak}

Summary: The article suggests ways of word formation in English and German languages. The notion and meaning of word formation in linguistic system and comparison of two languages in one morphological aspect are considered. In the course of the article several main kinds of word-formation and the main differences between compounding and affixation in German and English have been pointed out.

Keywords: language, word, word formation, lexical composition, compounding, affixation.
Литвяк Олеся Валерьевна

К.филол.н., дочент, Крымский инженерно-педагогический университет имени Февзи Якубова, г. Симферополь ole.litviak@yandex.ru

Аннотация: В статье предлагаются к рассмотрению способы словообразования в английском и немецком языках. Рассматриваются понятие и значение словообразования в языковой системе и в сравнении двух языковых систем в одном морфологическом аспекте. В ходе работы над статьей были выделены и проанализированы основные виды словообразовательных процессов в представленных языках, а также обозначены главные отличия между словосложением и аффиксацией в немецком и английском языках.

Ключевые слова: язык, слово, словообразование, лексический состав, словосложение, аффиксация.

ния и аффиксации, указать место словообразования в языковой системе представленных языков германской группы.

Предметным исследованием для анализа послужили лексемы немецкого и английского языков, образованные по принципу словосложения и аффиксации. Теоретической основой для написания данной научной статьи послужили работы учёных-лингвистов таких, как М.Д. Степанова, В. Флейшер, Х. Марчанд.

Основными путями развития словарного состава немецкого и английского языка являются словообразование, изменение значения слова, приводящее к появлению омонимов и заимствований. Каждый из этих путей имеет свои особенности. С помощью словообразования и изменения значения язык обогащался новыми словами на основе уже существовавших в нем слов. С помощью заимствования словарный запас одного языка обогащается за счет словарного запаса другого языка.

Новые слова в языке создаются по определенным моделям - по сложившимся в языке типам: с помощью продуктивных словообразовательных морфем, аффиксов, с помощью композиции, когда две или более основы объединяются в одну, путем конверсии. Каждый из этих способов имеет свою типологию, которая зависит от общей типологической характеристики языка.

Структура слова тесно связана со словообразованием. В лексикологии проблема словообразования является актуальной, поскольку она имеет большое значение в формировании языка и расширении лексикона, а различные способы словообразования часто используются 
в английских текстах и устной речи.

Для германских языков характерны основные принципы словообразования. Два наиболее важных процесса словообразования - это словосложение и аффиксация. Кроме того, новые слова могут образовываться путем конверсии, то есть переноса слова в другую синтаксическую категорию без явного морфологического маркирования. Апофония или чередование гласных, традиционно называемое аблаутом в индоевропейской лингвистике, происходит только в закрытых наборах родственных устоявшихся слов и является непродуктивным: оно не может быть продуктивно использовано для словообразования. Однако устоявшиеся слова этого типа могут использоваться в качестве составных частей соединений. Редупликация, копирование слов или их частей, является межъязыковым механизмом словообразования, но играет незначительную роль в германских языках. Также, существуют различные способы сокращения слов в более короткие, например, для выражения ласки, и смешение слов также встречается в германских языках [5].

Понятия «полусуффикс» и «полупрефикс» являются одним из способов словообразования, первые упоминания появляются в отечественной лингвистике одновременно с термином «semi-suffix» в зарубежной англистике. Англист X. Марчанд под «semi-suffix» определяет такие элементы, которые занимают промежуточную позицию между вторыми компонентами сложных слов и суффиксами. К полусуффиксам он относит такие морфемы, как -like, -worthy, -monger, -way, -wise, -wort. Эти морфемы, по мнению Х. Марчанд, принадлежат именно к полусуффиксам, так как, выступая только в составе производного, они проявляют «характер» самостоятельного слова [1]

Все германские языки имеют сильные и слабые глаголы, то есть они образуют прошедшее время и причастия прошедшего времени либо путем изменения корневого гласного в случае сильных глаголов (как в английском lie, lay, lain и в немецком ringen, rang, gerungen), либо путём добавления окончания -d (или -t) или -ed в случае слабых глаголов (как в английском look, looked, looked и немецком fragen, fragte, gefragt). Также типично германским является образование родительного падежа единственного числа путем добавления -s или -es. Примеры: английский man, man's, немецкий Lehrer, Lehrers или Mann, Mannes. Кроме того, сравнение прилагательных в германских языках происходит по параллельной схеме, как в английском: rich, richer, richest; немецком reich, reicher, reichst; и шведском rik, rikare, rikast. [6]

Другие способы глагольного словообразования, а именно префиксация и суффиксация, представлены в современном немецком языке в меньшей степени.
Наиболее продуктивными префиксами, используемыми при создании глаголов посредством префиксации, являются ver-, be-, ent-, er- и zer-, например, в предложении «Wegen dieser Rückstände hier entkalken wir mit kaltem, gelieferten Wasser... und nicht mit Wasser aus dem Hahn, weißt du noch?», глагол entkalken - «удалять известковые отложения, накипь» (kalken - белить известью или удобрять известью») [2].

Проблема «полуаффикса» остается открытой, так как они приобрели обобщенное лексико-категориальное значение, которое трактуется как словообразовательное, и в то же время не потеряли семантической связи с исходными самостоятельными лексемами. М.Д. Степанова предлагает выделяет следующие критерии: 1) формальное совпадение с основой свободно функционирующего слова; 2) этимологическую связь с данным словом; 3) серийность, то есть употребление не в одном, а в ряде слов; 4) семантическое сходство с соответствующим словом при большей или меньшей степени переосмысления. Таким образом М.Д. Степанова выделяет следующие глагольные полупрефиксы: с постоянным ударением - ab-, an-, auf-, aus- bei-, ein-, mit-, nach-, vor-, neben-, zu; с колеблющимся ударением - durch-, hinter-, über-, um-, unter-, wider- [3].

Будучи многогранным и сложным явлением, словосложение, с одной стороны, часто переплетается с аффиксацией и другими средствами словообразования, с другой стороны, находится на границе с синтаксисом. Особенно продуктивным является композиция как способ образования немецких существительных, которые отличаются большим разнообразием своего морфологического состава. Префиксация - то же, что и композиция, очень древний, но продуктивный способ словообразования. Стоит отметить, что почти все имеющиеся префиксы образуются в современном немецком языке. Суффиксацию также можно отнести к продуктивным способам словообразования в современном немецком языке. Однако, несмотря на ряд особенностей, объединяющих суффикс и полусуффикс, можно говорить о явных преимуществах в словообразовании полусуффиксов перед суффиксами. Но многие варианты расширенных суффиксов непродуктивны, например, -aner, -aster, -iener, -eiser, -ianer, -iter, -ner, -ser. Иноязычные аффиксы практически не участвуют в словообразовании с немецкими основами. Также, полусуффиксы, сохраняющие часть глубинной семантической структуры, более информативны, а основной целью коммуникации является передача информации. В отличие от суффиксации, словообразование путем изменения корня как самостоятельный способ является непродуктивным в современном языке, хотя слова, образованные таким способом, очень многочисленны [6].

Словосложение - это способ словообразования, при 
котором слово образуется путем соединения двух или более основ в одно слово. Структурное единство сложного слова зависит от: а) единства ударения, б) твердого или гифенированного написания, В) семантического единства, г) единства морфологического и синтаксического функционирования. Это характерные признаки сложных слов во всех языках. Но как правило, английские сложные слова имеют одно объединяющее ударение (обычно на первом компоненте), например, hard-cover, best-seller. В английских соединениях также может быть двойное ударение, когда основное ударение приходится на первый компонент, а второстепенное - на второй, например, blood-vessel. Третья схема ударений - это два уровня ударений, например, snow-white, sky-blue [5].

Английские соединения обладают единством морфологического и синтаксического функционирования. Они используются в предложении как одна его часть, и только один компонент изменяется грамматически, например, «These girls are chatter-boxes», «Chatter-boxes» является предикативом в предложении, и только второй компонент изменяется грамматически. Есть две характерные особенности английских соединений. Первое, когда оба компонента в английском сложном предложении - свободные основы, то есть они могут использоваться как слова с собственным значением. Звуковой рисунок будет одинаковым, за исключением ударений, например, «a green-house» $и$ «a green house». В то время как, например, в русских соединениях основы, как правило, являются связанными морфемами. Другая особенность, когда английские соединения имеют двухосновную структуру, за исключением сложных слов, которые имеют в своей структуре формообразующие основы, например, middle-of-the-road, off-the-record, up-and-doing и т.п. Такая модель отличает английские соединения от немецких.

Как и английский, немецкий язык также предлагает возможность объединения слов, особенно существительных. Получающиеся в результате цепочки существительных в английском языке обычно содержат пробелы или дефисы между различными элементами, в то время как в немецком они обычно выглядят как одно слово. Немецкая склонность к созданию сложных составных существительных давно стала предметом комедии. Марк Твен посвятил часть своего эссе «Ужасный немецкий язык» этим «явлениям», и многие люди знакомы с такими, как «der Donaudampfschifffahrtsgesellschaftskap itän» (капитан Дунайской пароходной компании).

Основное немецкое сложное слово, состоит из двух словарных единиц, хотя возможны и более длинные цепочки, например, слово «die Sprachschule». Второй элемент, «Schule», называется «основным словом» (das Grundwort) и обозначает большую совокупность (в данном случае, школы), частью которой является составное существительное. Оно также определяет род и форму множественного числа составного существительного. Первый элемент «Sprach» называется «определителем», или «определяющим элементом» (das Bestimmungswort). Он обозначает подмножество категории, которую определяет основное слово. Таким образом, «Sprachschule»это школа, в которой преподают языки.

Следовательно, разница между немецкими и английскими соединениями заключается в том, как они пишутся. В то время как английские соединения обычно пишутся как отдельные слова, немецкие соединения обычно пишутся как одно очень длинное слово.

Разберем эту разницу на примере для слова sprechen [4]:

\begin{tabular}{|l|l|}
\hline die Sprechstunde & office hours, consultation session \\
\hline die Sprachwissenschaft & linguistics (language science) \\
\hline die Sprachschule & language school \\
\hline der Sprachunterricht & language instruction \\
\hline sprachbegabt & linguistically talented \\
\hline das Sprichwort & proverb \\
\hline die Sprachkenntnisse & language skills \\
\hline
\end{tabular}

Немецкий язык является так называемым «левосторонним» языком, поэтому соединения создаются (и, следовательно, подлежат расшифровке) в обратном порядке. Другими словами, ключевой информацией является последний компонент соединения, а предшествующие элементы добавляют дополнительную информацию по мере продвижения влево. В результате род составного существительного определяется последним элементом соединения.

Словосложение и аффиксация тесно связаны между собой. Аффикс - это элемент грамматики, который используется для изменения значения или формы слова и бывает в виде префикса или суффикса. Префиксы включают такие примеры, как un-, self- и re-, а суффиксы имеют такие окончания, как -hood, -ing или -ed.

В то время как префиксы обычно сохраняют класс слова (например, существительное, глагол или прилагательное), которое они изменяют, суффиксы часто полностью меняют форму, как в случае с exploration по сравнению с ехplore или highlighter по сравнению с highlight.

В германских языках аффиксация, как префиксация, так и суффиксация, используется преимущественно для образования новых слов. Эти процессы используются для образования всех основных категорий: существительных, глаголов, прилагательных и наречий. Многие аффиксы современного немецкого языка возникли на основе компонентов сложных слов. Этот процесс естественен и исторически оправдан. В результате десемантизации второй компонент слова имеет такие суффиксы, 
как -schaft, -heit, -tum, -sam, -bar и др. Суффиксы не всегда сохраняют свой звуковой состав. Например, -schaft, -tum образованы от старонемецкого существительноro scaft, tuom со значением «Beschaffenheit», «Zustand», «Eigenschaft». Поскольку значение второго компонента носитель языка не угадывает, он является лишь средством словообразования и не обладает лексическим значением. Со временем суффикс может получить и другие значения. Суффикс -heit в средневерхненемецкий период обозначал «Weise», «Art», «Lage». Это значение существует и сегодня в некоторых диалектах.
Процессы словообразования очень распространены как в английском, так и в немецком языках, которые, по сути, имеют общую историю. Эти два языка широко используют различные процессы словообразования для обогащения своих словарей. Однако, несмотря на определенное сходство между двумя анализируемыми в данной статье языками, их различные пути эволюции и, косвенно, различные лексические влияния, оказанные на них с течением времени, определили отличительные особенности, когда речь идет о процессе словообразования.

\section{ЛИТЕРАТУРА}

1. Морозова Е.А. Тенденции словообразования современного немецкого языка (полуаффиксация) // Актуальные вопросы современной науки. 2011. №171. URL: https://cyberleninka.ru/article/n/tendentsii-slovoobrazovaniya-sovremennogo-nemetskogo-yazyka-poluaffiksatsiya (дата 0бращения: 21.09.2021)

2. Пащенко М.В. Словообразование как способ пополнения глагольного лексикона в современном немецком языке // Вестник СамГУ. 2008. №64.2.

URL: https://cyberleninka.ru/article/n/slovoobrazovanie-kak-sposob-popolneniya-glagolnogo-leksikona-v-sovremennom-nemetskom-yazyke (дата обращения: 21.09.2021).

3. Степанова, М.Д. Словообразование современного немецкого языка / М.Д. Степанова. - М.: КомКнига, 2007. - 376 с

4. Miscellaneous:Wortbildung// Grimm Grammar [Electronic source]/URL: https://www.coerll.utexas.edu/gg/gr/mis_02.html (дата 0бращения: 19.09.2021).

5. The basic ways of word formation. Modern word formation// StukLopechat.COM [Electronic source]/URL: https://stuklopechat.com/obrazovanie/85144-0snovnyesposoby-slovoobrazovaniya-sovremennoe-slovoobrazovanie. (дата обращения: 17.09.2021).

6. Word Formation in German Linguistics: Theoretical and Methodological Analysis// Scientific Research An Academic Publisher [Electronic source]/ URL:https://www.scirp.org/journal/paperinformation.aspx?paperid=87188\#ref9 (дата обращения: 18.09.2021).

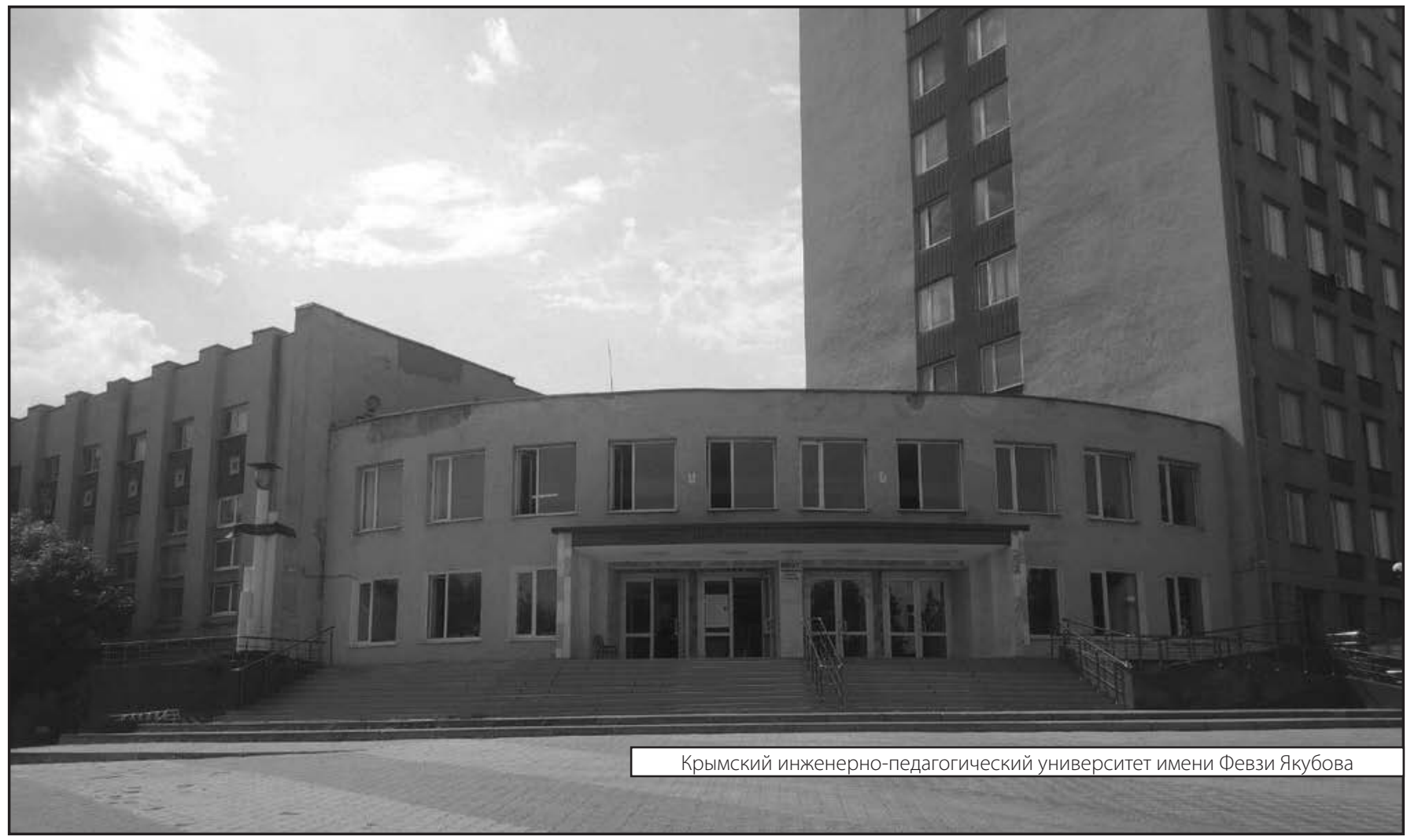

